\title{
RESPONS FISIOLOGIS DAN KETAHANAN PANAS KAMBING BOERAWA DAN PERANAKAN ETTAWA PADA MODIFIKASI IKLIM MIKRO KANDANG MELALUI PENGKABUTAN
}

\section{Physiological Responses and Heat Tolerance Ability of Boerawa and Ettawa Crossbreed Goat in the Microclimate Modification with Misting}

\section{Arif Qisthon dan Madi Hartono}

Department of Animal Husbandry, Faculty of Agriculture, University of Lampung Jl. Soemantri Brojonegoro No. 1, Gedong Meneng, Rajabasa, Bandar Lampung 35145

Email: arqisthon@gmail.com

\begin{abstract}
This research aimed to study the effect of microclimate modification of pensby misting and the goats breeds (Boer and Ettawa crossbreeds) on physiological responses to adapt to the hot environments. The study was conducted from August-September 2018 at the UPTD Goat Breeding Center, Lampung Plantation and Livestock Service Office located in Negeri Sakti, Pesawaran Regency. The study used a split plot design in completely randomized design. Two treatments were applied in this study, namely modification of the pen consisting of pens without misting and pens with misting and the goat breed namely Boerawa and Ettawa crossbreed (PE). Twelve female goats were used in this study, each of six Boerawa and PE respectively. The parameters observed were microclimate conditions, namely air temperature, relative humidity, and Temperature Humidity Index (THI) and physiological responses consisted of respiration rate, heart rate, rectal temperature, and Heat Tolerance Coefficient (HTC). The results showed that there was no effect of the interaction between the treatment of misting and the breeds of goat on respiration rate, heart rate, rectal temperature, and HTC. Misting can improve air temperature, THI, respiration rate and HTC, on the other hand, does not affect the heart rate and rectal temperature. Goat breed has no effect on all physiological responses. Thus, modification of the microclimate by misting effectively maintains body temperature under normal conditions and increases the adaptability of goats to hot environments.
\end{abstract}

Keywords: Physiological Responses, Microclimate Conditions, Microclimate Modification, Misting

\section{PENDAHULUAN}

Suhu dan kelembaban lingkungan, serta radiasi matahari yang tinggi merupakan kendala dalam pengembangan dan peningkatan produktivitas ternak di Indonesia, khususnya di wilayah dataran rendah, karena menyebabkan cekaman panas pada ternak. Cekaman panas yang terjadi menunjukkan bahwa toleransi atau adaptasi ternak terhadap iklim sekitarnya rendah. Konsekuensi dari cekaman panas atau toleransi panas yang rendah secara langsung adalah terjadinya penurunan produktivitas ternak, baik pertumbuhan, produksi susu, maupun reproduksi. Mabjeesh et al. (2013) melaporkan bahwa terjadi penurunan produksi susu pada kambing yang terkena cekaman panas. Parameter lain yang menunjukkan cekaman panas adalah adanya perubahan fisiologis dan tingkahlaku, yaitu penurunan nafsu makan dan metabolisme, peningkatan konsumsi air minum, peningkatan pengeluaran panas melalui evaporasi; penurunan konsentrasi hormon metabolis dalam darah, peningkatan suhu tubuh, frekuensi pernafasan, dan denyut jantung (Qisthon dan Suharyati, 2007; Aguilar et al., 2010; dan Seixas et al., 2017).

Kendala iklim di atas perlu diantisipasi sehingga akan berdampak pada perbaikan produktivitas ternak. Memodifikasi kandang dapat dilakukan untuk memperbaiki mikroklimat sehingga menghasilkan lingkungan yang lebih nyaman. Beberapa teknik modifikasi lingkungan mikroklimat untuk mengantisipasi dampak negatif suhu udara tinggi dalam kandang telah dilaporkan oleh para peneliti, seperti penggunaan naungan atau atap, penyiraman air, penggunaan kipas angin (Marcillac-Embertson et al., 2009; Koluman dan Daskiran, 2011; Boonsanit et al., 
2012; Worley, 2012; Ohnstad, 2013), modifikasi rancang bangun kandang (Brouk et al., 2001; Worley, 2012), dan pengkabutan kandang (House, 2002 dan Palulungan, 2012). Efektivitas hasil dari berbagai teknik tersebut bervariasi, namun secara umum dapat menurunkan cekaman panas.

Pada lingkungan panas, mekanisme termoregulasi akan aktif untuk mengeluarkan panas agar suhu tubuh tetap normal. Mekanisme ini melibatkan kerja sistem respirasi, sirkulasi, ekskresi, endokrin, dan syaraf (Seixas et al., 2017). Mekanisme tersebut bervariasi di antara spesies, bangsa, dan individu dalam bangsa yang sama. Oleh karena itu, informasi respons fisiologis dan daya adaptasi ternak terhadap iklim panas pada berbagai bangsa kambing di suatu wilayah sangat diperlukan.

Parameter lingkungan yang umum digunakan untuk mengevaluasi cekaman panas adalah temperatur-humidity index (THI) yang merupakan satu nilai dari kombinasi suhu dan kelembaban lingkungan yang merujuk pada beban panas ternak. Selain parameter lingkungan, parameter fisiologis yang biasa digunakan untuk mengukur daya adaptasi ternak terhadap lingkungan panas adalah heat tolerance coefficient (HTC) yang dihitung berdasarkan suhu rektal yang dikembangkan oleh Rhoad (Seixas et al., 2017) maupun kombinasi suhu rektal dan frekuensi respirasi yang dikembangkan oleh Benezra (Seixas et al., 2017 dan Thakare et al., 2017).

Modifikasi kandang dengan pengkabutan telah banyak dilakukan pada sapi perah, namun belum banyak diaplikasikan pada kambing. Oleh karena itu penting dipelajari aplikasi pengkabutan dalam kandang untuk mengevaluasi daya adaptasi terhadap lingkungan panas kambing Boerawa dan Peranakan Ettawa (PE). Dari penelitian ini diharapkan menghasilkan temuan berupa informasi daya adaptasi kambing dan efektifitas teknik modifikasi iklim mikro kandang dalam mengatasi cekaman panas ternak kambing.

\section{MATERI DAN METODE}

Penelitian dilaksanakan di kandang UPTD Balai Pembibitan Ternak Kambing, Dinas Perkebunan dan Peternakan Lampung yang berlokasi di Negeri Sakti, Kabupaten Pesawaran. Penelitian berlangsung pada Agustus hingga September 2018. Ketinggian lokasi penelitian sekitar $300 \mathrm{~m}$ dpl dengan suhu lingkungan 25,9$32,5{ }^{\circ} \mathrm{C}$ Sebanyak 12 ekor kambing digunakan pada penelitian ini masing-masing 6 ekor Boerawa dan Peranakan Ettawa (PE) dengan bobot tubuh awal 26-31 kg dan umur 1-2,5 tahun. Peralatan yang digunakan diantaranya mistfan sebanyak 2 buah (Misty Cool ${ }^{\circledR}$, type DH650, 26 inc, $1.400 \mathrm{r} / \mathrm{min}$ ), dry-wet bulb thermometer, dan stetoskop.

Penelitian menggunakan rancangan Split Plot dengan rancangan dasar acak lengkap. Dua perlakuan diterapkan dalam penelitian ini, yaitu perlakuan modifikasi iklim mikro kandang yang terdiri kandang tanpa pengkabutan (TP) dan kandang dengan pengkabutan $(\mathrm{P})$ serta perlakuan pada bangsa kambing Boerawa (B) dan kambing Peranakan Ettawa (PE). Bangsa kambing sebagai anak petak dan modifikasi iklim mikro kandang sebagai petak utama. Kambing ditempatkan secara individual pada petak-petak berukuran 200 x $100 \mathrm{~cm}$ dalam kandang tipe panggung dengan atap terbuat dari asbes.

Pengambilan data penelitian berlangsung empat minggu. Pengkabutan kandang dengan mistfan yang diletakkan setinggi 1,8 $\mathrm{m}$ dari lantai di depan ternak. Pengkabutan dilakukan setiap hari dari pukul 11.00-14.00. Saat berlangsungnya pengkabutan, keempat sisi dinding kandang ditutup dengan tirai terpal. Konsentrat pabrik diberikan pukul 07.00 dan 16.00, sedangkan hijauan pukul 08.00 dan 17.00. Air minum diberikan secara ad libitum

Parameter yang diamati terdiri atas iklim mikro (suhu udara, kelembaban udara relatif (RH), dan temperatur humidity index (THI)), dan kondisi fisiologis (suhu rektal, frekuensi respirasi, frekuensi denyut jantung, heat tolerance coefficient (HTC)). Iklim mikro diamati setiap hari pada setiap jam mulai pukul 07.00-16.00. Temperatur humidity index dihitung berdasarkan formulasi yang dipergunakan Thompson dan Dahl (2012) yaitu :

$$
\begin{aligned}
\mathrm{THI}= & (1,8 \times \mathrm{T}+32)-[(0,55-0,0055 \times \mathrm{RH}) \times \\
& (1,8 \times \mathrm{T}-26)]
\end{aligned}
$$

Keterangan :

$\mathrm{T} \quad=$ Suhu udara $\left({ }^{\circ} \mathrm{C}\right)$

$\mathrm{RH}=$ Kelembaban udara $(\%)$

Parameter fisiologis diukur seminggu sekali sesaat menjelang pengkabutan (10.3011.00) dan segera setelah pengkabutan (14.0014.30). Cara pengukuran dilakukan menurut Qisthon et al. (2018), yaitu suhu rektal diukur dengan memasukkan termometer klinis digital ke dalam rektum kambing dan ujungnya menyentuh mucosa hingga terdengan bunyi alarm dari termometer (sekitar 1-2 menit). Frekuensi respirasi diukur dengan cara menghitung pergerakan naik-turun di daerah flank selama satu 
menit. Frekuensi denyut jantung diukur dengan cara menempelkan stetoskop di dada sebelah kiri selama satu menit. Heat tolerance coefficient dihitung dengan rumus Benezra (Thakare et al., 2017) menggunakan data suhu rektal dan frekuensi respirasi yang diperoleh, yaitu:

$$
\mathrm{HTC}=(\mathrm{RT} / 39,44)+(\mathrm{RR} / 24)
$$

Keterangan :

RT $=$ suhu rektal $\left({ }^{\circ} \mathrm{C}\right)$

RR = frekuensi respirasi (kali/menit);

$39,44=$ suhu rektal normal kambing $\left({ }^{\circ} \mathrm{C}\right)$

$24=$ respirasi normal kambing (kali/menit)

Data fisiologis dianalisis dengan sidik ragam dan uji-t untuk data mikroklimat dengan bantuan software statistik IBM-SPSS ver.20.

\section{HASIL DAN PEMBAHASAN}

\section{Kondisi Iklim Mikro Kandang}

Rataan suhu udara, kelembaban, dan THI kandang terlihat pada Tabel 1. Rataan suhu kandang tanpa pengkabutan sangat nyata $(\mathrm{P}<0,01)$ lebih tinggi daripada kandang dengan pengkabutan, demikian pula pada THI. Kondisi suhu udara kandang masih dalam batas toleransi bagi kambing sebagaimana pendapat Lu (1989) bahwa batas toleransi suhu lingkungan bagi kambing berkisar $25-30^{\circ} \mathrm{C}$. Namun demikian, interaksi suhu dan kelembaban akan berpotensi menyebabkan kambing mengalami cekaman panas. Indikasi cekaman panas tersebut terlihat dari nilai THI yang mencapai 80-83,7. Hamdan et al. (2018) menyatakan bahwa nilai THI normal jika $<74,75-78$ adalah status siaga, 79-83 status bahaya dan sangat berbahya apabila nilai THI $>84$.

Pengkabutan mampu memperbaiki kondisi klimat kandang menjadi lebih baik dengan menurunkan suhu maupun THI. Hasil ini sesuai dengan penelitian Chanchai et al. (2010) bahwa suhu udara dan THI pada kandang tanpa pengkabutan signifikan lebih tinggi dari kandang dengan tambahan pengkabutan. Kondisi lingkungan yang lebih nyaman tersebut akan menurunkan beban panas ternak, sehingga diharapkan dapat menampilkan produktivitas yang lebih baik.

Kelembaban kedua kandang relatif sama dan cukup tinggi, lebih besar dari kisaran kelembaban optimum yang dibutuhkan oleh kambing, yaitu sekitar $75 \%$ (Smith dan Mangkuwidjojo, 1988). Tingginya kelembaban tersebut dapat menyebabkan ternak mengalami kesulitan dalam melepaskan panas tubuh ke lingkungan melalui jalur evaporatif, sehingga memperberat beban panas (heat load) yang dialami ternak.

Tabel 1 . Kondisi mikro klimat kandang

\begin{tabular}{lccc}
\hline \multicolumn{1}{c}{ Kandang } & Suhu Udara $\left({ }^{\circ} \mathbf{C}\right)$ & RH $(\%)$ & THI \\
\hline $\begin{array}{l}\text { Tanpa } \\
\text { Pengkabutan }\end{array}$ & $30,2 \pm 1,6^{\mathrm{a}}$ & $80,9 \pm 5,3$ & $83,3 \pm 2,3^{\mathrm{a}}$ \\
$\begin{array}{l}\text { Dengan } \\
\text { Pengkabutan }\end{array}$ & $28,6 \pm 1,4^{\mathrm{b}}$ & $80,6 \pm 5,1$ & $80,7 \pm 1,7^{\mathrm{b}}$ \\
\hline
\end{tabular}

Keterangan: Huruf superskrip yang berbeda pada kolom yang sama menunjukkan sangat berbeda $(\mathrm{P}<0,01)$

\section{Pengaruh Perlakuan terhadap Respons Fisiologis}

\section{a. Frekuensi respirasi}

Rataan frekuensi respirasi kambing selama penelitian disajikan pada Tabel 2. Frekuensi respirasi kambing berkisar antara 34,8 dan 44 kali/menit. Hasil analisis ragam menunjukkan bahwa tidak terdapat pengaruh interaksi $(\mathrm{P}>0,05)$ antara perlakuan pengkabutan dan bangsa kambing terhadap respons frekuensi respirasi. Selanjutnya, faktor pengkabutan sangat nyata $(\mathrm{P}<0,01)$ berpengaruh terhadap respons frekuensi respirasi, sebaliknya faktor bangsa kambing tidak berpengaruh $(\mathrm{P}>0,05)$.

Frekuensi respirasi kedua bangsa kambing berada di atas kisaran normal, yaitu 10-20 kali per menit (Smith dan Mangkuwidjoyo,1988). Kondisi ini disebabkan nilai THI yang mencapai lebih dari 80, sehingga sistem termoregulasi kambing melalui jalur respirasi untuk melepaskan beban panas tubuh ke lingkungan menjadi aktif dan meningkat.

Kambing pada kandang tanpa pengkabutan menunjukkan tingkat cekaman panas yang lebih besar yang terlihat dari lebih tingginya frekuensi respirasi dibandingkan dengan kambing dengan pengkabutan. Hasil ini sejalan dengan penelitian sebelumnya dengan sapi perah, yaitu frekuensi respirasi signifikan lebih tinggi pada kandang tanpa pengkabutan dibandingkan dengan pada kandang dengan pengkabutan (Chanchai et al., 2010 dan 
Boonsanit et al., 2012). Peningkatan cekaman panas pada perlakuan tanpa pengkabutan diakibatkan oleh perolehan panas dari lingkungan (heat gain) yang diindikasikan dengan peningkatan suhu udara dan THI. Bernabucci et. al. (2010) menyatakan bahwa peningkatan frekuensi respirasi merupakan salah satu respons segera yang dilakukan ternak yang terkena cekaman panas. Peningkatan frekuensi respirasi merupakan salah satu mekanisme termoregulasi untuk menjaga suhu tubuh tidak ikut meningkat dan relatif konstan. Peningkatan pernafasan menyebabkan panas tubuh bagian dalam akan cepat dialirkan oleh darah ke saluran respirasi dan selanjutnya dikeluarkan melalui evaporasi.

Tabel 2. Respons fisiologis dan HTC kambing

\begin{tabular}{|c|c|c|c|c|}
\hline \multirow[b]{2}{*}{ Perlakuan } & \multicolumn{4}{|c|}{ Parameter } \\
\hline & $\begin{array}{c}\text { RR } \\
\text { (kali/menit) }\end{array}$ & $\begin{array}{c}\text { HR } \\
\text { (kali/menit) }\end{array}$ & $\begin{array}{c}\text { TR } \\
\text { (kali/menit) }\end{array}$ & HTC \\
\hline \multicolumn{5}{|l|}{ Modifikasi mikro klimat } \\
\hline a. Tanpa Pengkabutan & $42,8 \pm 1,77^{\mathrm{a}}$ & $75,8 \pm 0,2^{\mathrm{a}}$ & $38,7 \pm 0,1^{\mathrm{a}}$ & $2,8 \pm 0,1^{\mathrm{a}}$ \\
\hline b. Dengan Pengkabutan & $35,7 \pm 1,18^{\mathrm{b}}$ & $72,0 \pm 3,3^{\mathrm{a}}$ & $38,6 \pm 0,1^{\mathrm{a}}$ & $2,5 \pm 0,1^{\mathrm{b}}$ \\
\hline \multicolumn{5}{|l|}{ Bangsa Kambing } \\
\hline a. Boerawa & $40,3 \pm 5,3^{\mathrm{a}}$ & $75,0 \pm 0,9^{\mathrm{a}}$ & $38,7 \pm 0,1^{\mathrm{a}}$ & $2,7 \pm 0,2^{\mathrm{a}}$ \\
\hline b. Peranakan Ettawa & $38,2 \pm 4,7^{\mathrm{a}}$ & $72,8 \pm 4,8^{\mathrm{a}}$ & $38,6 \pm 0,1^{\mathrm{a}}$ & $2,6 \pm 0,2^{\mathrm{a}}$ \\
\hline \multicolumn{5}{|l|}{ Interaksi } \\
\hline $\begin{array}{l}\text { Modifikasi mikroklimat * Bangsa } \\
\text { kambing }\end{array}$ & tn & tn & tn & tn \\
\hline
\end{tabular}

Penurunan frekuensi respirasi kambing dalam kandang yang dikabut diduga diakibatkan oleh penurunan suhu permukaan tubuh setelah pengkabutan sehingga memungkinkan terjadinya pelepasan panas tubuh ke lingkungan yang lebih besar melalui konduksi, konveksi, dan evaporasi. Hal ini berakibat pada penurunan kecepatan pelepasan panas melalui saluran respirasi agar panas yang dibuang ke lingkungan tidak berlebihan dan suhu tubuh tetap konstan.

Kambing Boer dan PE memiliki frekuensi pernafasan yang relatif sama. Hal ini menunjukkan bahwa kemampuan adaptasi pada lingkungan panas kedua bangsa kambing tersebut tidak berbeda dan kemungkinan disebabkan keduanya yang berasal dari daerah tropis sehingga sudah beradaptasi.

\section{b. Frekuensi denyut jantung}

Rataan frekuensi denyut jantung kambing selama penelitian berkisar dari 69,7-76 kali/menit (Tabel 2). Hasil analisis ragam menunjukkan bahwa tidak terdapat pengaruh interaksi $(\mathrm{P}>0,05)$ antara perlakuan pengkabutan dan bangsa kambing terhadap frekuensi denyut jantung. Selanjutnya, baik perlakuan pengkabutan maupun bangsa kambing masing-masing juga tidak menunjukkan adanya pengaruh terhadap frekuensi denyut jantung $(\mathrm{P}>0,05)$.
Frekuensi denyut jantung semua kambing baik di kandang tanpa pengkabutan maupun dengan pengkabutan masih dalam kisaran normal, yaitu 70-80 kali per menit (Dukes, 1985). Menurut Astuti et al. (2015), meningkatnya denyut jantung bertujuan untuk mengatur tekanan darah dan membantu mengedarkan panas dari organ tubuh bagian dalam ke permukaan tubuh. Pada penelitian ini, kondisi cekaman panas yang tinggi sehingga ternak memaksimalkan pelepasan panas tubuh ke lingkungan dengan jalur respirasi. Pada cekaman panas tinggi, sebagian besar mekanisme pelepasan panas akan efektif melalui respirasi, sehingga frekuensi denyut jantung relatif tidak banyak meningkat.

\section{c. Suhu rektal}

Rataan suhu rektal berkisar antara 38,55 dan $38,76^{\circ} \mathrm{C}$ (Tabel 2). Analisis ragam menunjukkan bahwa tidak terdapat pengaruh interaksi yang nyata $(\mathrm{P}>0,05)$ antara perlakuan pengkabutan dan bangsa kambing terhadap respons suhu rektal. Selanjutnya, baik perlakuan pengkabutan maupun bangsa kambing juga tidak menunjukkan adanya pengaruh terhadap suhu rektal $(P>0,05)$. Pada sapi perah penambahan pengkabutan nyata menurunkan suhu rektal (Boonsanit et al., 2012). Hasil yang berbeda tersebut diduga berkaitan dengan kemampuan 
adaptasi terhadap lingkungan panas pada kambing yang lebih baik dibandingkan dengan sapi perah.

Suhu rektal semua kambing percobaan masih dalam kisaran normal. Menurut Aye (2007), suhu rektal normal untuk domba dan kambing berkisar $32,60^{\circ} \mathrm{C}$ sampai $39,60^{\circ} \mathrm{C}$. Dalam kondisi cekaman panas ternak akan mengaktifkan mekanisme termoregulasi, ternak akan memperbesar pelepasan panas tubuh ke lingkungan guna mempertahankan suhu tubuh tetap dalam kondisi normal. Pada penelitian ini sangat terlihat bahwa pelepasan panas dilakukan dengan jalur respirasi yang meningkat di atas normal (Tabel 2), baik pada kandang pengkabutan maupun tanpa pengkabutan. Dengan demikian dapat dinyatakan bahwa mekanisme termoregulasi ternak berjalan dengan baik karena suhu tubuh dapat dipertahankan dalam kisaran normal.

\section{d. Heat Tolerance Coefficient}

Heat tollerance coefficient merupakan nilai yang digunakan untuk mengetahui kemampuan adaptasi ternak terhadap kondisi panas atau ketahanan panas di suatu wilayah. Hasil analisis ragam memperlihatkan bahwa pengaruh interaksi antara perlakuan pengkabutan dan bangsa kambing tidak nyata $(\mathrm{P}>0,05)$ terhadap nilai HTC (Tabel 2). Selanjutnya, diketahui bahwa perlakuan bangsa kambing tidak berpengaruh $(\mathrm{P}>0,05)$ terhadap nilai HTC, sebaliknya nilai HTC pada kandang dengan pengkabutan lebih baik dibandingkan tanpa pengkabutan $(\mathrm{P}<0,01)$.

Perlakuan pengkabutan mampu menurunkan nilai HTC mendekati 2 dibandingkan dengan kandang tanpa pengkabutan. Hal ini menunjukkan bahwa pengkabutan dapat meningkatkan daya adaptasi ternak terhadap kondisi lingkungan. Sebaliknya ternak pada kambing tanpa pengkabutan akan lebih keras berusaha beradaptasi terhadap lingkungan klimat dengan meningkatkan frekuensi respirasi.

Nilai HTC kambing Boer cenderung lebih tinggi dibandingkan dengan kambing PE, meskipun secara statistik tidak berbeda. Kondisi ini mengindikasikan bahwa kambing PE memiliki kemampuan menyesuaikan dengan lingkungan klimat sekitarnya relatif lebih baik.

\section{SIMPULAN}

Tidak terdapat pengaruh interaksi antara perlakuan pengkabutan dan bangsa kambing terhadap respons frekuensi respirasi, denyut jantung, suhu rektal, dan HTC kambing. Pada perlakuan bangsa kambing juga tidak berpengaruh pada respons frekuensi respirasi, denyut jantung, dan suhu rektal, serta daya adaptasi kambing, sedangkan pada aplikasi pengkabutan dalam kandang efektif memperbaiki respons frekuensi respirasi dan ketahanan panas kambing.

\section{DAFTAR PUSTAKA}

Aguilar, I., I. Misztal, and S. Tsuruta. 2010. Short communication:Genetic trends of milk yield under heat stress for US Holstein. $J$. Dairy Sci. 93:1754-1758

Astuti, A., Erwanto, dan P. E. Santosa. 2015. Pengaruh cara pemberian konsentrat hijauan terhadap respon fisiologis dan perforam sapi Peranakan Simental. Jurnal Ilmiah Peternakan Terpadu 3(4):201-7.

Aye, P. A. 2007. Production of Multi-Nutrient Blocks for Ruminants and Alcohol from Waste Products of Leucaena and Gliricidia Leaves Using Local Technologies. Federal University of Technology Akure.

Boonsanit, D. S., Chanpongsang, and N. Chaiyabutr. 2012. Effects of supplemental recombinant bovine somatotropin and mist-fan cooling on the renal tubular handling of sodium in different stages of lactation in crossbred Holstein cattle. Research in Vet. Sci. 93:417-426.

Bernabucci, U., N. Lacetera, L.H. Baumgard, R. P. Rhoads, B. Ronchi, and A. Nardone. 2010. Metabolic and hormonal acclimation to heat stress in domestic ruminants. Animal 4 (7):1167-1183.

Brouk, M.J., J.F. Smith, J.P. Harner. 2001. Facility and Climate Effects on Dry Matter Intake of Dairy Cattle. Proceedings of the 5th Western Dairy Management Conference, April 4-6, Las Vegas, Nevada. In Arizona and New Mexico Dairy Newsletter Cooperative Extension, The University of Arizona New Mexico State University, May 2005. http://www. publish.csiro.au/?act=view file\&file $\underline{\mathrm{id}=\mathrm{SA} 0501219 . \mathrm{pdf}}$. Diakses pada 19 September 2013.

Chanchai, W., S. Chanpongsang and N. Chaiyabutr. 2010. Effects of cooling and supplemental recombinant bovine somatotropin on diet digestibility, digestion kinetics and milk production of cross-bred Holstein cattle in the tropics. $J$. Agric. Sci. 148(2): 233-242

Dukes. 1985. Physiology of Domestic Animal. Comstock Publishing New York University Collage. Camel. 
Hamdan, A., B.P. Purwanto, D.A. Astuti, A. Atabany, dan E. Taufik. 2018. Respons kinerja produksi dan fisiologis kambing peranakan ettawa terhadap pemberian pakan tambahan dedak halus pada agroekosistem lahan kering di Kalimantan Selatan. Pengkajian dan Pengembangan Teknologi Pertanian 12(1) : 73--84.

House, H. 2002. Keeping Cool - Set Up Supplemental Fans Now to Comfort Cows Next Summer. http://www. omafra.gov.on.ca/english/livestock/dairy/f acts/info keeping.htm. Diakses pada 15 Oktober 2013

Koluman, N. and I. Daskiran. 2011. Effects of ventilation of the sheep house on heat stress, growth and thyroid hormones of lambs. Trop. Anim. Health Prod. 43: 1123-1127.

Lu, C.D. 1989. Effect of Heat Stress on Goat Production. Elseiver science publisher B.V. Amsterdam

Mabjeesh, S.J., C. Sabastian, O. Gal-Garber, and A. Shamay. 2013. Effect of photoperiod and heat stress in the third trimester of gestation on milk production and circulating hormones in dairy goats. $J$. Dairy Sci. 96 :189-197.

Marcillac-Embertson, N.M., P.H. Robinson, J.G. Fadel, and F.M. Mitloehner. 2009. Effects of shade and sprinklers on performance, behavior, physiology, and the environment of heifers. J. Dairy Sci. 92: 508-517.

Ohnstad,, I. 2013. Managing Heat Stress in Dairy Cows. National Animal Disease Information Service (NADIS). http://www.nadis.org.uk/bulletins/managi ng-heat-stress-in-dairy-cows.aspx? altTemplate $=$ PDF. Diakses pada 26 September 2013.

Palulungan, J.A. 2012. Pengaruh Kombinasi Pengkabutan dan Kipas Angin terhadap
Kondisi Fisiologis Sapi Perah Peranakan Fries Holland. Tesis. Program Pascasarjana Fakultas Peternakan Universitas Gadjah Mada. Yogyakarta.

Qisthon, A. dan S. Suharyati. 2007. Pengaruh naungan terhadap respons termoregulasi dan produktivitas kambing Peranakan Ettawa. Majalah Ilmiah peternakan, 10(1): 13-16.

Qisthon, A., W. Busono, P. Surjowardojo, S. Suyadi. 2018. Pengaruh penyiraman air dan penganginan tubuh pada musim hujan terhadap respons fisiologis dan produksi susu sapi perah PFH di dataran rendah. Prosiding. Seminar Persepsi III: Strategi dan Kebijakan Pengembangan Bisnis Peternakan dalam Mendukung Kedaulatan Pangan Nasional. Universitas Sam Ratulangi. Manado.

Seixas, L., C.B. de Melo, C.B. Tanure, V. Peripolli, and C. Mc.Manus. 2017. Heat tolerance in Brazilian hair sheep. AsianAustralasian J. Anim. Sci. 30(4): 593-601.

Smith, J.B. dan S. Mangkuwidjoyo. 1988. Pemeliharaan, Pembiakan dan Penggunaan Hewan Percobaan di Daerah Tropis. Cetakan Pertama. Penerbit UI. Jakarta.

Thakare, P.D., A.R. Sirothia, and A.R. Sawarkar. 2017. Heat tolerance ability and its variability in different breeds of goat with reference to pulse rate. Int. J. Current Innovation Research 3(9): 805-806

Thompson, I.M. and G.E. Dahl. 2012. Dry-period seasonal effects on the subsequent lactation. Professional Animal Scientists 2012: 628-631.

Worley, J.W. 2012. Cooling Systems for Georgia Dairy Cattle. The University of Georgia. http://www.caes.uga.edu/applications/pub lications/files/pdf/B\%201172 4.PDF. Diakses pada 23 September 2013. 